\title{
Surgical Management of Recurrent and Persistent Macular Holes: A Practical Approach
}

Jessica L. Cao · Peter K. Kaiser

Received: June 8, 2021 / Accepted: August 9, 2021 / Published online: September 7, 2021

(C) The Author(s) 2021

\section{ABSTRACT}

Primary surgery for macular hole $(\mathrm{MH})$ closure has a high success rate with current methods of pars plana vitrectomy and internal limiting membrane (ILM) peeling. When primary surgery fails, there are several options available for secondary repair, including extension of the ILM peel, creation of an ILM flap, pedunculated ILM flap, lens capsule flap transplantation, autologous retinal transplantation, use of a human amniotic membrane plug, adjuvant autologous platelet concentrate, induction of macular detachments with subretinal blebs, and creation of retinal incisions. In this review, we discuss the practical approach to each of these surgical techniques for the management of recurrent or persistent MHs.

Keywords: ILM; Macular hole; Surgery; Vitrectomy

This article is based on previously conducted studies and does not contain any new studies with human participants or animals performed by any of the authors.

J. L. Cao · P. K. Kaiser $(\bowtie)$

Cole Eye Institute, Cleveland Clinic, 9500 Euclid

Ave, i-32, Cleveland, OH 44195, USA

e-mail: pkkaiser@gmail.com

\section{Key Summary Points}

A full-thickness macular hole (MH) is a full-thickness break within the fovea that can cause decreased vision.

Primary surgery for MH has a high success rate with current methods of pars plana vitrectomy and internal limiting membrane (ILM) peeling.

When primary surgery fails, several secondary surgical options exist for recurrent or persistent MHs.

In this review, we discuss each surgical technique in detail.

\section{INTRODUCTION}

A full-thickness macular hole (MH) is defined as a full-thickness break within the fovea that can cause a significant decrease in vision. The annual incidence has been reported to be between 4.05 and 8.69 eyes per 100,000 population per year $[1,2]$. The prevalence is reported to be between 0.14 and $0.7 \%$ in the general population [3-7]. There is a female-to-male 
predominance, and the incidence of MHs appear to increase with age $[1,8-11]$.

The primary closure rate for macular holes is greater than $90 \%$ with current methods, which consist of a pars plana vitrectomy with or without internal limiting membrane (ILM) peeling, and gas endotamponade [12-18]. Peeling of the ILM has been significantly associated with lower rates of reoperation in a recent, large, retrospective, cross-sectional study [19].

The management of recurrent and persistent MHs can be challenging for vitreoretinal surgeons. After closure, macular holes may reopen in approximately $3.3-9.2 \%$ of cases, and larger holes are more likely to fail primary surgery [20-25]. Fortunately, a second surgery can result in anatomic closure. In one study by Valldeperas and Wong, reoperation on reopened macular holes resulted in anatomic closure in $100 \%$ of 21 cases [20]. In the same case series, $76 \%$ of patients who had persistent holes without initial closure achieved successful anatomic closure after the second surgery but final vision was poorer than in those with initial closure. In another study of 103 patients with failed primary macular hole surgery, $85 \%$ of 53 reoperated eyes showed hole closure. Vision improved but may take some time to occur [26].

\section{RISK FACTORS FOR FAILURE OF PRIMARY MACULAR HOLE SURGERY}

Primary surgical repair may fail due to various factors, including persistent vitreoretinal and epiretinal traction, chronicity of the hole, inadequate gas endotamponade, large aperture diameter, high myopia, or MHs with a flat-open configuration [27-31]. The benefit of face-down positioning after $\mathrm{MH}$ surgery remains unclear, but it is possible that it may benefit MHs larger than 400 microns [29, 32, 33].

In general, the prognosis for closure is correlated with the size of the hole [27, 34, 35]. The larger the base diameter and minimal extent of the hole, the higher the likelihood of surgical failure and poorer postoperative visual function [35]. If a second surgery is pursued, the type of surgical technique utilized may depend on the surgeon's comfort and experience. In our review, we describe the current literature on surgical management options for recurrent and persistent MHs. Table 1 provides a summary of studies.

\section{SURGICAL TECHNIQUES}

\section{Internal Limiting Membrane Peel}

In 1991, Kelly and Wendel reported the first series of patients to undergo successful vitreous surgery for idiopathic MHs [36]. After their cohort of 52 patients underwent pars plana vitrectomy, epiretinal membrane (ERM) stripping, a gas-fluid exchange, and face-down positioning for at least 1 week, 30 (58\%) experienced $\mathrm{MH}$ closure. Of these 30 patients, 73\% $(22 / 30)$ had at least a two-line improvement in visual acuity. Seven had no significant change in vision and one showed a significant decline in vision. They also showed a slight negative correlation between visual acuity and duration of symptoms.

Surgery for $\mathrm{MH}$ closure was revolutionized when Eckardt et al. introduced internal limiting membrane (ILM) peeling in 1997 [15]. Speciallydesigned forceps were used to remove a circular area of ILM measuring three to four disc diameters in size from around the hole. This was followed by C3F8 gas endotamponade and facedown positioning. With this technique, 36 of 39 eyes (92\%) had full closure of their $\mathrm{MH}$ and $77 \%$ achieved at least two lines of visual acuity improvement. Similar results were found when Park et al. looked at 58 eyes that underwent ILM peeling (at least $1000 \mu \mathrm{m}$ from the $\mathrm{MH}$ edge) followed by air endotamponade and face-down positioning [37]. With a single surgery, 91\% of eyes had successful $\mathrm{MH}$ closure. The number of eyes that had a visual acuity of at least 20/50 increased from 5 (9\%) eyes preoperatively to 31 (53\%) eyes postoperatively. In this study, 14\% of eyes were classified as stage $2,83 \%$ as stage 3 , and $3 \%$ as stage 4 . Long term, ILM peeling has proven to be safe. In 64 eyes with follow-up of at least 36 months (median 62 months, mean 56 months), 95\% achieved anatomical MH closure without late reopening and best-corrected 


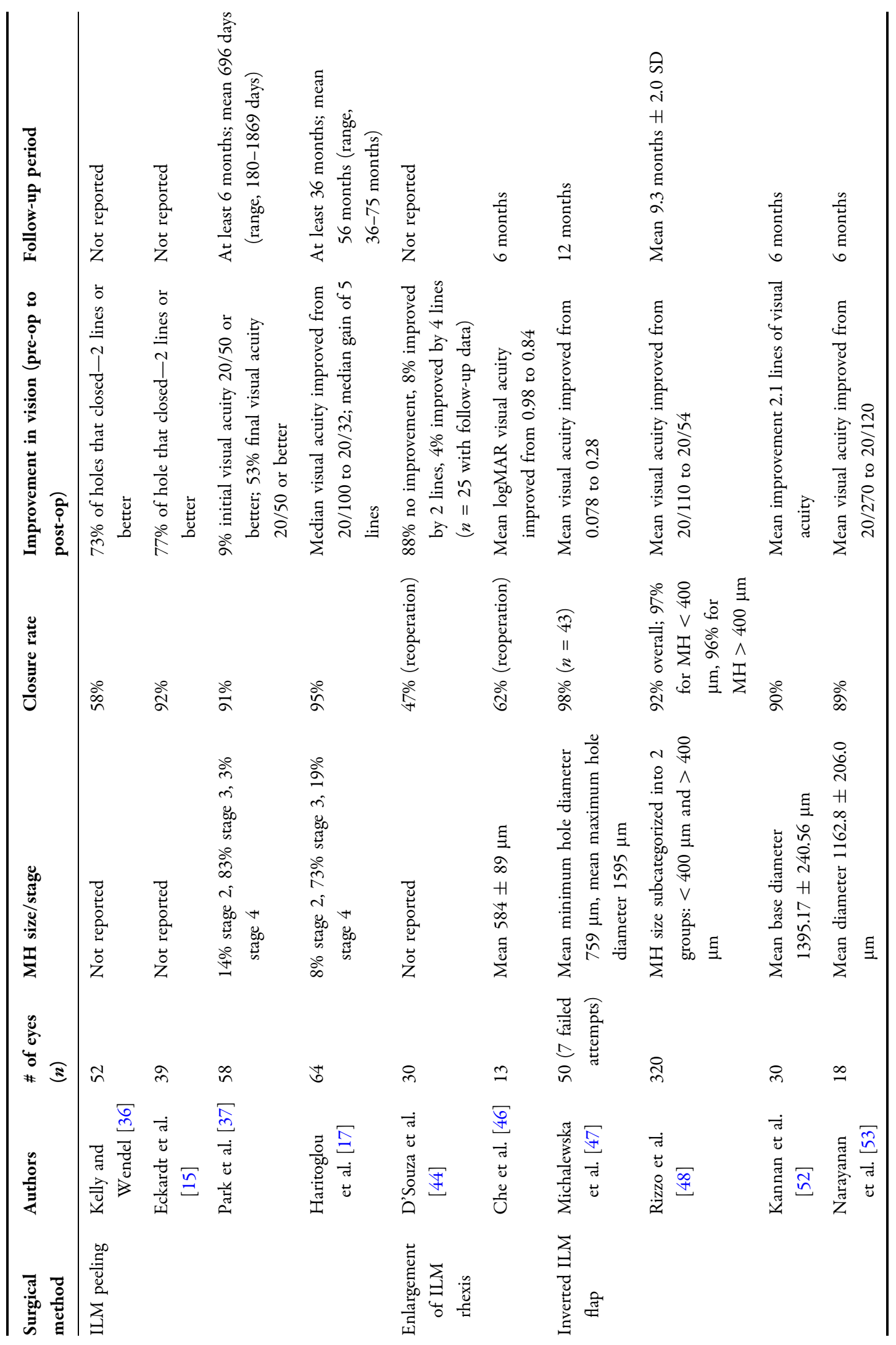




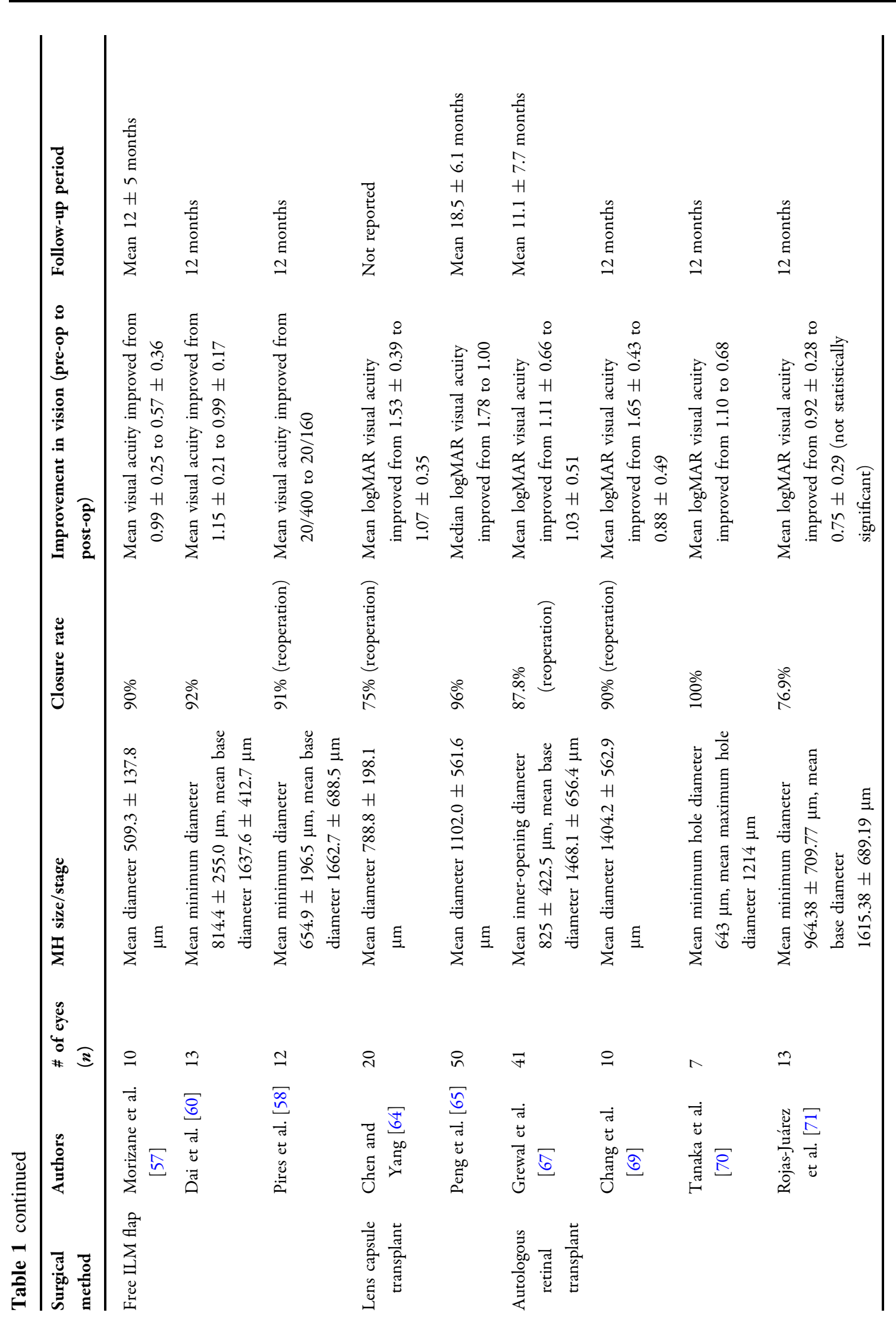




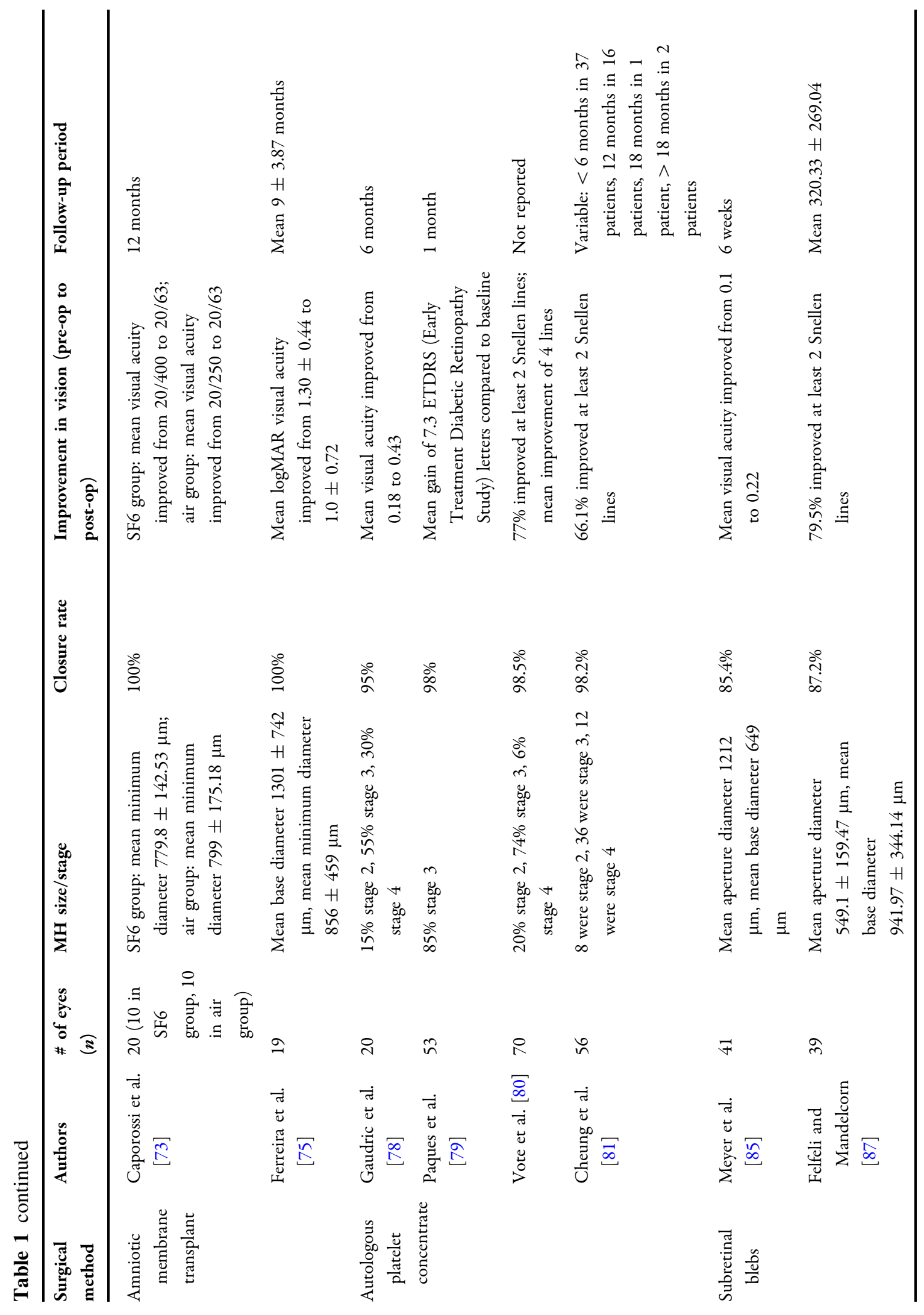




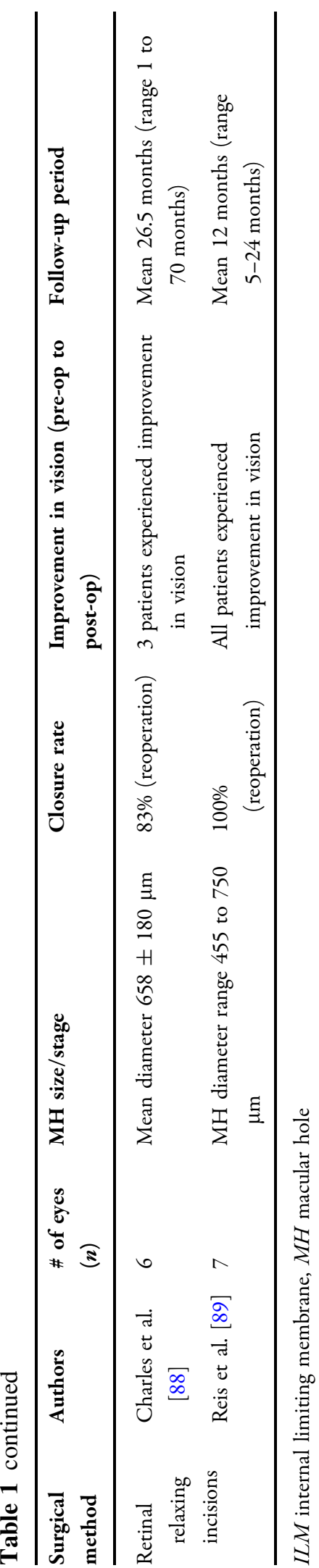

visual acuity improved in $92 \%$ of eyes [17]. In this study, there was a median gain of five lines of vision postoperatively. Eight percent of these eyes were stage $2,73 \%$ were stage 3 , and $19 \%$ were stage 4 .

A subsequent comparative study found that ILM peeling significantly improved primary closure rates when compared to eyes that did not undergo ILM peeling [38]. When comparing 44 eyes without ILM peeling to 116 eyes with ILM peeling, only 36 of 44 eyes without ILM peeling achieved primary closure versus $100 \%$ of 116 eyes that achieved primary closure when ILM was peeled $(p<0.00001)$. In eyes without ILM peeling, a greater percentage of stage 3 holes ( $24 \%$ of 25 eyes) had primary failure compared to stage 2 holes (12\% of 17 eyes) [39]. In addition, visual acuity after ILM peeling was significantly better compared to eyes without ILM peeling. Other comparative studies found a similar advantage to ILM peeling versus no ILM peeling. In a series by Sheidow et al., 43 of 44 $(97.7 \%)$ of eyes with ILM peeling without indocyanine green (ICG) staining and 34 of 35 (97.1\%) of eyes with ICG-assisted ILM peeling had primary $\mathrm{MH}$ closure compared to only 75 of 97 (77.3\%) eyes in a group without ILM peeling [13]. ILM peeling also increased the patients' chances of developing at least 20/50 vision (odds ratio 2.4; 95\% confidence interval $1.06-5.45 ; p=0.04)$. While the anatomic benefit of ILM peeling has been corroborated in several other comparative trials, its effect on functional outcomes is less clear, with several studies finding no significant difference in ILMpeeled and non-ILM-peeled eyes [14, 16, 40].

More recently, the use of indocyanine green (ICG) dye to stain the ILM has facilitated its visualization, which may improve $\mathrm{MH}$ closure rates [41, 42]. In eyes that fail primary surgery despite ICG-assisted ILM peeling, re-staining and enlarging the prior peel may result in an increase in closure rate. In a series of nine eyes with persistent/recurrent $\mathrm{MH}$ that underwent additional ILM peeling, all eyes had closure of the $\mathrm{MH}$ after the second surgery and experienced statistically significant improvement in postoperative visual acuity [43]. In another study of 55 patients who had failed primary closure or had reopened during follow-up, 30 
underwent a second surgery with enlargement of the ILM rhexis [44]. Fourteen of the 30 eyes (46.7\%) achieved secondary closure and an improvement in best corrected visual acuity $(p=0.02)$. Two other series in which eyes underwent additional ILM peeling showed a secondary closure rate between 61.5 and $68.9 \%$ with an improvement in vision $[45,46]$.

\section{Internal Limiting Membrane Flap}

Providing a scaffold over the $\mathrm{MH}$ for tissue proliferation is another approach that has been shown to lead to $\mathrm{MH}$ closure in difficult cases. In 2010, Michalewska et al. described the use of an inverted ILM flap for MH closure and found that it improved both anatomic and functional outcomes for $\mathrm{MHs}$ greater than $400 \mu \mathrm{m}$ in diameter [47]. In their study of 43 eyes that successfully underwent the inverted ILM flap technique, the mean minimum and maximum $\mathrm{MH}$ diameters were $759 \mu \mathrm{m}$ and $1595 \mu \mathrm{m}$, respectively. There was a $98 \% \mathrm{MH}$ closure rate after the first surgery and patients experienced a statistically significant improvement in vision 12 months after surgery. In this technique, ERM peeling is followed by circumferential peeling of ILM two disc diameters around the $\mathrm{MH}$. The ILM is left attached to the MH edge and trimmed down, then the ILM remnant is gently inverted upside-down over the $\mathrm{MH}$ until it is covered. The authors believe that this technique works by introducing Müller cells that induce glial cell proliferation. Compared to standard ILM peeling, the ILM flap technique improved closure rate, the anatomic configuration of the fovea, and the postoperative visual acuity. Additional studies found a similar anatomic benefit of the inverted ILM flap over conventional ILM peeling in myopic eyes with MHs [48-50]. While another study by Manasa et al. also found superior outcomes for the inverted ILM flap technique in holes of at least $600 \mu \mathrm{m}$ in size, additional trials looking at similarly sized MHs did not find a benefit in anatomical or visual outcomes, and the results appear mixed for these larger MHs (at least $600 \mu \mathrm{m}$ in diameter) [51-53].
Several variations of the ILM flap have been described, including a semicircular ILM peel with a temporally hinged inverted flap, a circular ILM peel with temporally hinged inverted flap, and circular ILM peel with superior inverted flap, with studies suggesting comparable results amongst the different techniques $[54,55]$. Another variation is called the "Texas taco" technique and involves a semicircular peel of the nasal ILM beyond the temporal edge of the hole followed by draping of the ILM flap over the hole [56]. In all of these techniques, the principle is the same: to provide a scaffolding over the hole.

In cases with previously complete ILM peels, creation of an ILM flap may not be possible. In these eyes, the use of a free ILM flap or a pedunculated flap are options [57]. Morizane et al. described a technique in which a small piece of ILM peeled from the peripheral macula is used to create a free flap similar in diameter to the macular hole [57]. This is followed by stabilization of the flap with a viscoelastic tamponade within the hole. In their prospective series of 10 eyes, 9 eyes had successful closure and 8 eyes had significant improvement in visual acuity an average of 12 months after surgery [57]. The mean $\mathrm{MH}$ diameter in their series of patients was $509.3 \pm 137.8 \mu \mathrm{m}$. Similar results with high closure rates and improvements in vision have been reported in other similarly sized series with large MHs [58-60]. Maintaining the tissue within the hole may be difficult during air-fluid exchange, but use of perfluorocarbon or viscoelastic, as previously mentioned, can help tamponade the flap in place during this step of the surgery [61, 62]. The pedunculated flap is where an ILM flap larger than the radius of the hole to the edge of the previous ILM peel is fashioned with the hinge at the edge of the previous ILM peel. This allows the flap to lay across both the original ILM peel area and the hole. It goes without saying that this may be technically difficult as the ILM is increasingly thinner the further from the fovea one goes.

\section{Lens Capsule Transplant}

When ILM peeling or an ILM flap are difficult or not possible, the tissue of the lens capsule may 
provide an alternative scaffold to facilitate $\mathrm{MH}$ closure in recurrent or persistent cases $[63,64]$. Chen and Yang first described this technique in 2016 in a series of 20 eyes (mean MH diameter $788.8 \pm 198.1 \mu \mathrm{m}$ ) with prior history of a failed pars plana vitrectomy with ILM peel [64]. The procedure was performed by first staining the anterior (AC) or posterior capsule (PC) with ICG, followed by the creation of a capsule flap dependent on the patient's lens status. In phakic patients, combined cataract surgery was performed and the AC was harvested, and in pseudophakic patients, the PC was used. The flap was trimmed to a size slightly larger than that of the $\mathrm{MH}$ and placed within the hole with microforceps. Ten of 10 eyes with AC flap transplantation and 5 of 10 eyes with PC transplantation achieved complete hole closure, and vision was significantly improved [64].

The long-term results of this technique appear favorable. In a series of 50 eyes that had undergone either autologous or allogeneic lens capsule transplantation, the closure rate was $96.0 \%$ after a mean follow-up period of 18.5 months (mean $\mathrm{MH}$ diameter $1102.0 \pm 561.6 \mu \mathrm{m})$ [65]. This series also demonstrated an improvement in vision. Thirty-one of the 50 eyes also had simultaneous autologous whole-blood application which may reduce lens capsule dislocation during the procedure.

\section{Autologous Retinal Transplant}

In 2016, Grewal and Mahmoud introduced the use of an autologous full-thickness retinal free flap for closure of refractory myopic MHs [66]. Similar to the ILM flap and lens capsule flap, the retinal tissue provides a scaffold and plug for $\mathrm{MH}$ closure. They describe this technique in their first published case of a -15-diopter myopic woman with a complex history of failed vitrectomy with ILM peel for a MH followed by a scleral buckle and vitrectomy for retinal detachment repair. Additional ILM could not be harvested and she was pseudophakic with an open PC. During the procedure, they applied endolaser barricade and diathermy in a circular pattern around a 2-disc diameter area of retina and used a bimanual approach with vertical scissors and forceps to obtain a retinal free flap.
This was followed by instillation of perfluoro-noctane heavy liquid (PFC; Perfluoron; Alcon) over the flap and direct PFC-silicone oil exchange. After 3 months, her $\mathrm{MH}$ remained closed and vision improved.

In a multicenter case series of 41 eyes with macular holes refractory to prior vitrectomy with ILM peeling, $87.8 \%$ achieved anatomic hole closure after autologous retinal transplantation [67]. The study included MHs with a mean inner-opening diameter of $825 \pm 422.5$ $\mu \mathrm{m}$ and a mean base diameter of $1468.1 \pm 656.4$ $\mu \mathrm{m}$. The mean visual acuity improved in $36.6 \%$ of eyes, remained stable in $41.5 \%$ of eyes, and worsened in $21.9 \%$ of eyes. Similar anatomic success rates have been found in additional case series, though results for functional improvement have been less consistent [68-71]. In a recent prospective case series of 13 eyes with refractory MHs (mean minimum diameter $964.38 \pm 709.77 \mu \mathrm{m}$, mean base diameter $1615.38 \pm 689.19 \mu \mathrm{m})$, closure rate after 12 months was $76.9 \%$ with this technique but there was no statistically significant improvement in vision [71].

\section{Amniotic Membrane Transplant}

Rizzo et al. first reported the use of a human amniotic membrane (hAM) for $\mathrm{MH}$ closure in 2019 [72]. In their series of eight eyes with recurrent $\mathrm{MH}$ despite prior vitrectomy with ILM peeling, hAM was manipulated under fluid or perfluorocarbon (perfluorodecalin, Biofluor, Bucine [AR], Italy) and transplanted through the $\mathrm{MH}$ into the subretinal space. Afterwards, the patients underwent an air-fluid exchange and gas endotamponade, yielding a 100\% closure rate at 6 months of follow-up. It is believed that the hAM induces retinal pigment epithelium (RPE) cell proliferation and secretion of growth factors that facilitate retinal growth, as optical coherence tomography (OCT) scans obtained during the postoperative period demonstrated a fully stratified retinal layer over the patch of hAM. In a comparative study of 10 eyes with a hAM plug and $20 \%$ SF6 gas endotamponade versus 10 eyes with hAM plug and air endotamponade, all MHs were found to be closed after 12 months [73]. Both groups maintained face down positioning for 3 days 
and there was no statistically significant difference in $\mathrm{MH}$ size or postoperative visual acuity between the two groups. The mean minimum MH diameter was $779.8 \pm 142.53 \mu \mathrm{m}$ in the SF6 group and $799 \pm 175.18 \mu \mathrm{m}$ in the air group. Similar success rates have been reported in additional case series with the use of hAM for $\mathrm{MH}$ closure, though studies comparing this technique to others have not been published [74-76].
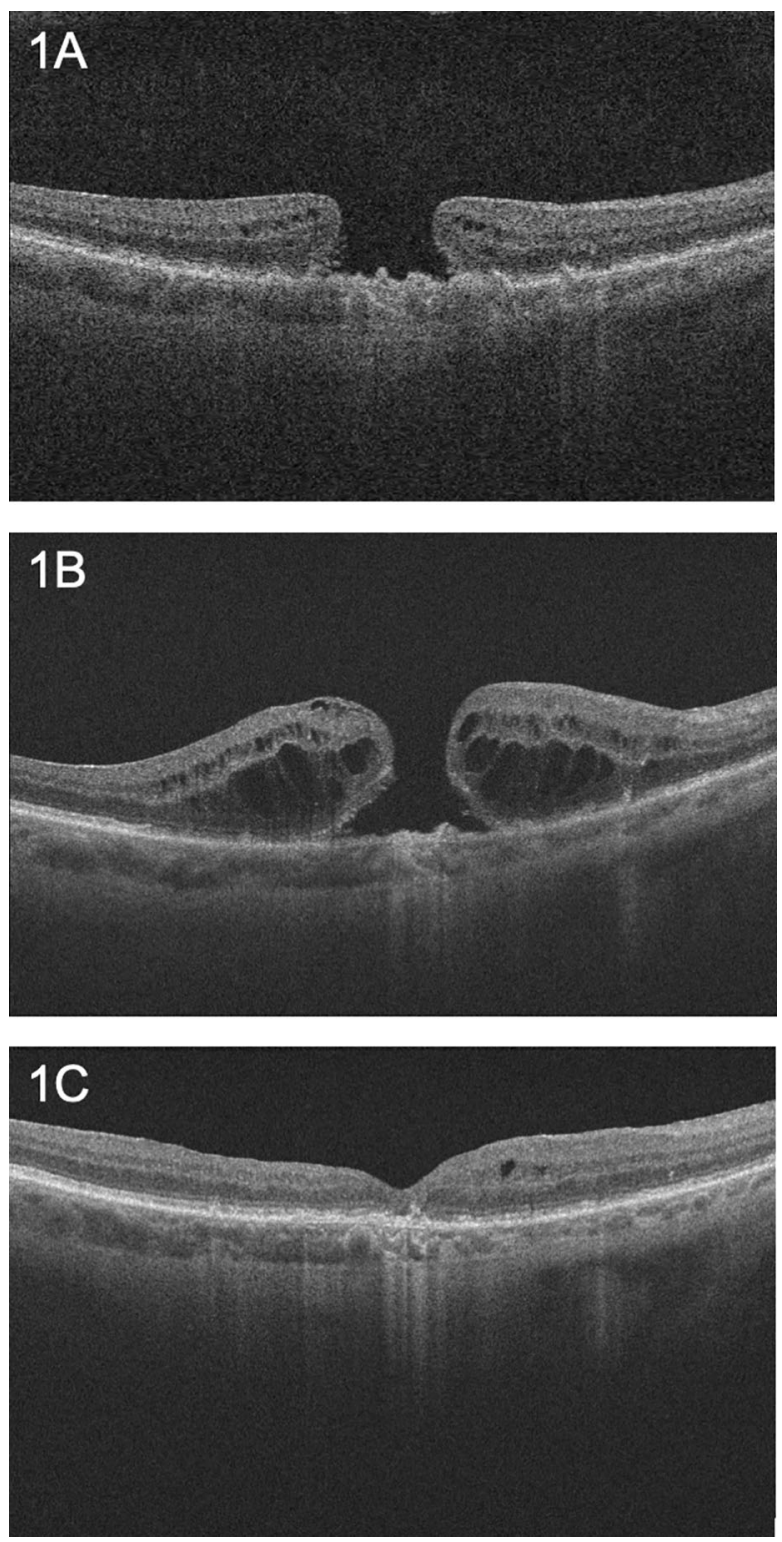

Fig. 1 FTMH closure after enlargement of the ILM rhexis

\section{Autologous Platelet Concentrate}

Autologous platelets are believed to contain growth factors and cytokines that may promote tissue healing [77]. Gaudric et al. decided to test the effects of autologous platelet concentrate (APC) by comparing two groups of patients with MHs, one with (group 1) and one without (group 2) an injection of autologous platelet concentrate (APC) after standard MH surgery [78]. They found a statistically significant difference in $\mathrm{MH}$ closure rate $(95 \%$ in group 1 versus $65 \%$ in group 2) but no difference in vision for successfully operated eyes between the two groups. They then studied 110 patients with stage 3 or $4 \mathrm{MHs}$ and randomized them to receive an APC injection or no APC injection after standard vitrectomy, posterior hyaloid separation, and fluid-gas exchange [79]. Their results were similar: the group that received an APC injection $(n=53)$ had a $98 \% \mathrm{MH}$ closure rate one month after surgery while the control group without an APC injection $(n=57)$ had an $82 \%$ closure rate $(p=0.009)$. However, when comparing successfully closed MHs, visual acuity was not significantly different between the groups.

In a study of 70 eyes that underwent vitrectomy with APC, primary anatomical closure rate was $95.7 \%$, though $8.5 \%$ of holes reopened a mean of 12.7 months after the initial surgery [80]. In this subset of patients, 14 eyes were classified as stage 2 holes, 42 as stage 3 holes, and 4 as stage 4 holes. After reoperation on reopened holes, final surgical success was $98.5 \%$, and $77.0 \%$ of patients experienced an improvement in visual acuity at final follow-up. Another review of 56 patients revealed a similar anatomical success rate of $98.2 \%$ with $66.1 \%$ experiencing functional improvement, defined as at least two lines of improvement in Snellen vision [81]. Of the 56 eyes, 8 were classified as stage 2, 36 as stage 3 , and 12 as stage 4 MHs. More recently, a comparative study evaluating ILM peeling versus ILM peeling plus plateletrich plasma (PRP) showed a significant improvement in anatomic and functional results in eyes that had adjuvant application of PRP [82]. While these results are encouraging, larger prospective comparative studies are necessary to corroborate these results. 

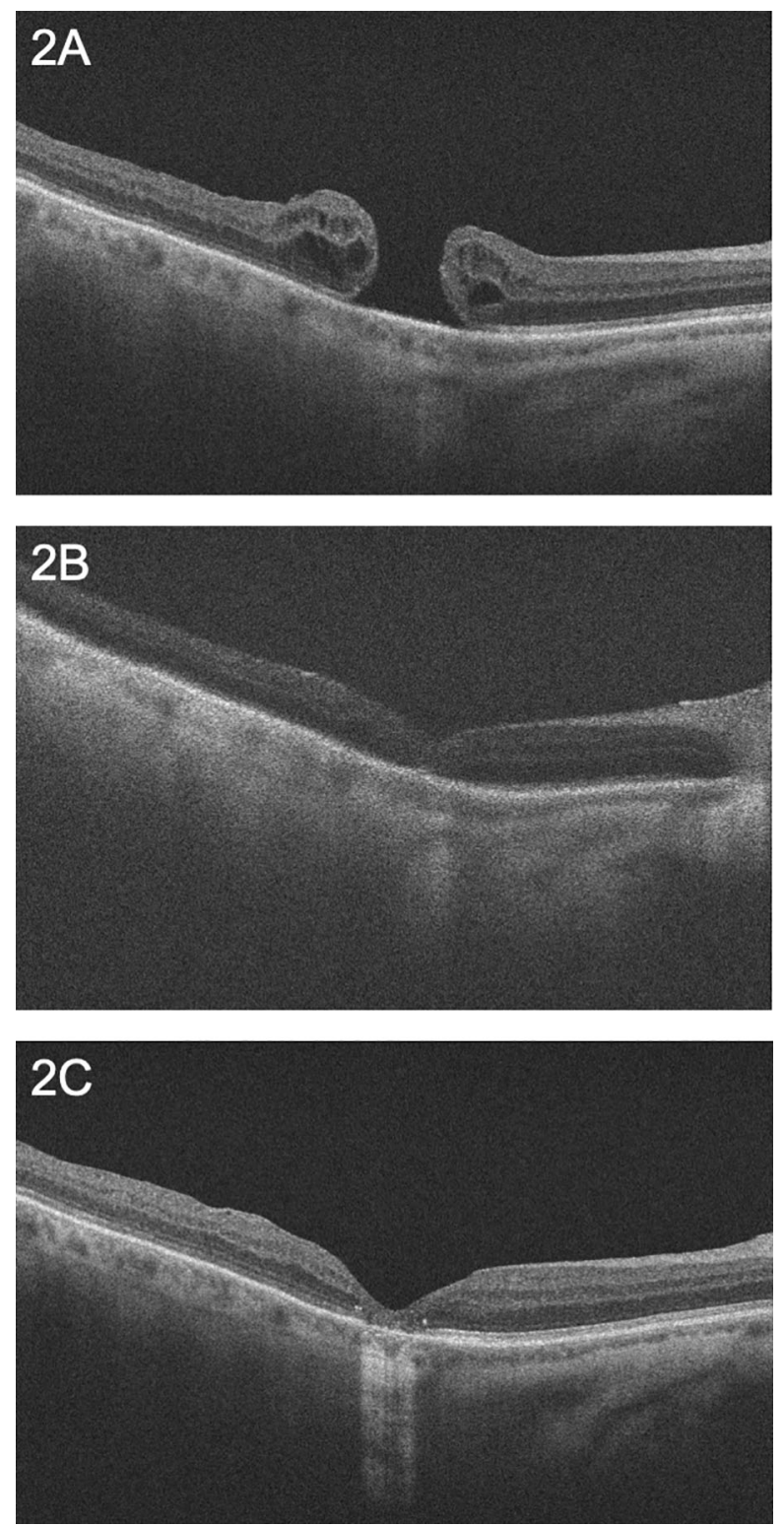

Fig. 2 FTMH closure after ILM flap

\section{Subretinal Blebs}

Induction of a localized macular detachment around the macular hole has also been shown to be a viable option for the closure of recurrent or persistent holes $[83,84]$. In this technique, a small-gauge subretinal cannula (38-gauge or 41-gauge) is connected to a syringe filled with balanced salt solution (BSS), and multiple BSS blebs are injected into the subretinal space surrounding the $\mathrm{MH}$. After additional BSS is injected and a confluent perifoveal serous detachment is induced, a Tano diamond dusted scraper or a Flex Loop is used to massage the released paracentral retina towards the foveal center. This is followed by an air-fluid exchange and either gas or silicone oil endotamponade. The technique is believed to work by releasing any firm adhesions of photoreceptors to the retinal pigment epithelium (RPE), allowing mobilization of the parafoveal retina. These adhesions are hypothesized to be one potential reason initial $\mathrm{MH}$ surgery fails despite the release of epiretinal traction.

Using this method, Meyer et al. achieved a closure rate of $85.4 \%$ in a case series of 41 eyes with large MHs (mean base diameter of 649 microns) [85]. In another series of ten eyes with persistent or recurrent $\mathrm{MH}$ after prior ILM peeling, 90\% experienced closure 6 months postoperatively with a statistically significant improvement [86]. Another study reported a similar closure rate of $87.2 \%$ in a series of 39 eyes with a mean $\mathrm{MH}$ base diameter of $941.97 \pm 344.14 \mu \mathrm{m}$ [87]. The mean postoperative vision was significantly improved and better in the closure compared with the nonclosure group.

\section{Retinal Relaxing Incisions}

Charles et al. presented a technique involving the creation of a full-thickness arcuate retinotomy temporal to a $\mathrm{MH}$ in a series of six eyes with large MHs (mean diameter $548 \pm 180 \mu \mathrm{m}$ ) that had failed primary repair [88]. Using this approach, five $(83 \%)$ of those eyes had successful $\mathrm{MH}$ closure and three (50\%) demonstrated an improvement in visual acuity. His technique is limited by its potential damage to the underlying RPE as evidence by postoperative retinal thinning and underlying RPE defect in some patients. Variations of this technique include the creation of five peri-foveal radial full-thickness incisions beginning one hole diameter away and ending at the margin of the hole or the creation of 120 degree arcuate relaxing retinotomies near the superotemporal and inferotemporal vascular arcades $[89,90]$. 

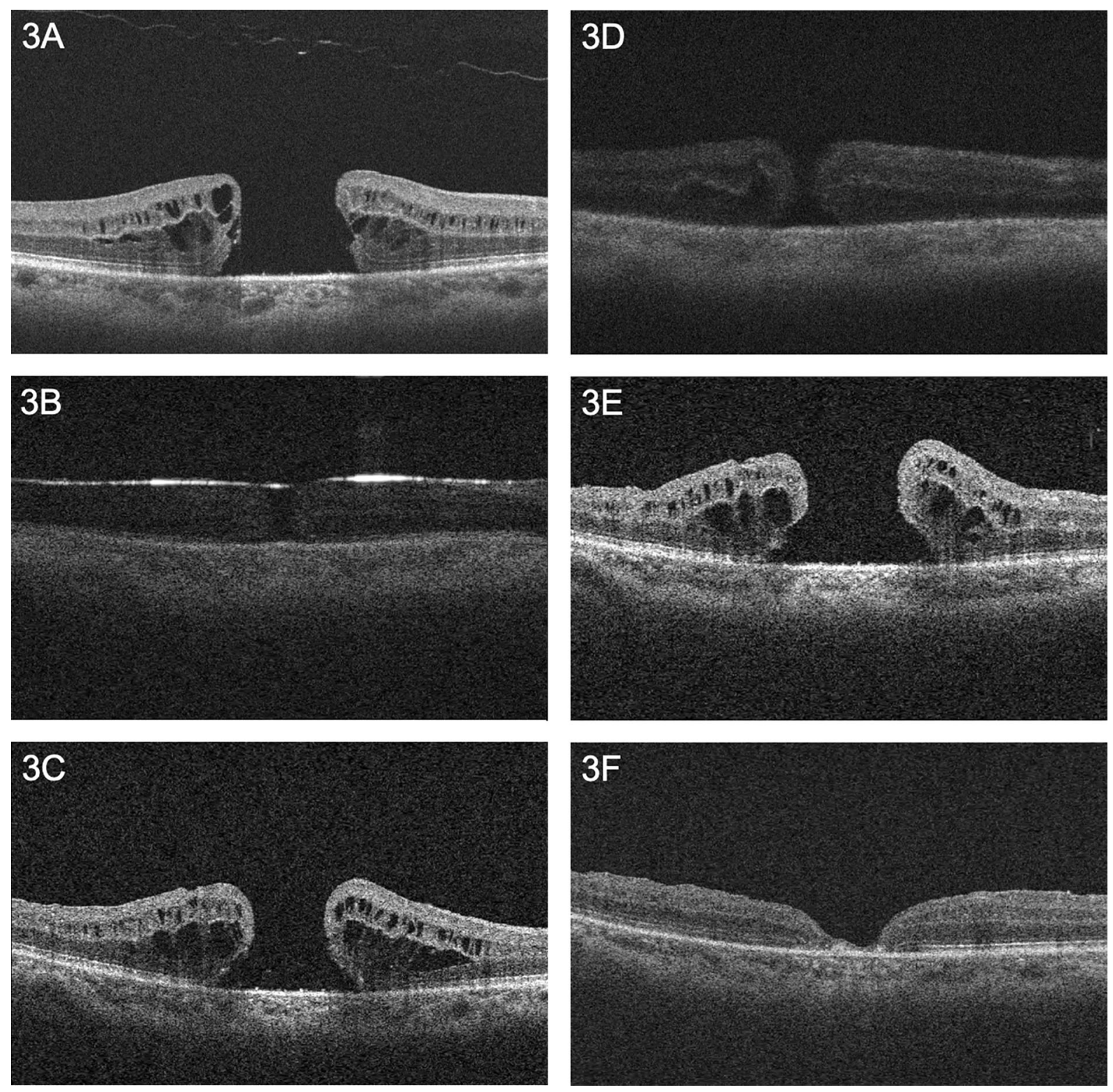

Fig. 3 FTMH closure after subretinal blebs

\section{CONCLUSIONS}

While primary anatomic closure rates for macular holes are high, complex cases that are recurrent or refractory can be challenging for vitreoretinal surgeons. Fortunately, there are numerous techniques that have been developed that may portend good anatomic and functional outcomes. Currently, there are no large, randomized studies directly comparing these techniques to one another, so the selection generally rests on the surgeon's personal preference and experience.

\section{Case Examples}

\section{Case 1: Enlargement of the ILM Rhexis}

A 73-year-old Caucasian woman with a history of non-exudative age-related macular degeneration (AMD) presented with decreased vision in 
her right eye for 3 months. Vision was count fingers, which had declined significantly from 20/30 1 year prior. On examination, she had a full-thickness $\mathrm{MH}$ and OCT confirmed a $\mathrm{MH}$ with a base diameter of $1020 \mu \mathrm{m}$ and a minimum diameter of $740 \mu \mathrm{m}$ (Fig. 1A). She underwent cataract surgery with intraocular lens placement, pars plana vitrectomy, ERM removal with creation of an ILM flap, and C3F8 gas endotamponade. Three months later, the hole remained open with a base diameter of $1230 \mu \mathrm{m}$ and a minimum diameter of $410 \mu \mathrm{m}$ (Fig. 1B). She underwent a second surgery with enlargement of the ILM rhexis and the hole remained closed at the postoperative month 6 visit and vision was 20/500 (Fig. 1C).

\section{Case 2: ILM Flap}

A 68-year-old Caucasian man presented for a second opinion for a persistent $\mathrm{MH}$ in his right eye. He had decreased vision for 2 months prior to undergoing pars plana vitrectomy with membrane peel and SF6 gas endotamponade. After the $\mathrm{MH}$ failed to close, he underwent repeat pars plana vitrectomy, membrane peel, and C3F8 gas endotamponade, which also failed to close the hole. He subsequently presented to the Cole Eye Institute with a vision of 20/200. An OCT revealed a full-thickness $\mathrm{MH}$ with a base diameter of $910 \mu \mathrm{m}$ and minimum diameter of $470 \mu \mathrm{m}$ (Fig. 2A). He underwent cataract surgery with intraocular lens placement, pars plana vitrectomy, an ILM flap, and C3F8 gas endotamponade. One week after surgery, an ILM flap was visible over a closed $\mathrm{MH}$ (Fig. 2B). The hole remained closed 8 months after surgery and vision improved to 20/50 (Fig. 2C).

\section{Case 3: Subretinal Blebs}

A 63-year-old African-American woman presented with declining vision in the right eye for 1 year. Vision was 20/80 and OCT showed a MH with a minimum diameter of $970 \mu \mathrm{m}$ and a base diameter of $1290 \mu \mathrm{m}$ (Fig. 3A). After pars plana vitrectomy with a membrane peel, ILM flap, and C3F8 gas endotamponade, the hole decreased in size but remained open (Fig. 3B). Two months after surgery, vision was 20/100. OCT showed a persistent $\mathrm{MH}$ with a minimum diameter of 770 $\mu \mathrm{m}$ and a base diameter of $1520 \mu \mathrm{m}$ (Fig. 3C). The patient underwent repeat pars plana vitrectomy with an ILM free flap, but the hole remained open on OCT 10 days after surgery (Fig. 3D). Three months after the second surgery, the $\mathrm{MH}$ persisted with a base diameter of $1710 \mu \mathrm{m}$ and a minimum diameter of $890 \mu \mathrm{m}$ (Fig. 3E). Vision remained unchanged at 20/100. The patient then underwent repeat pars plana vitrectomy with injection of BSS into the subretinal space surrounding the $\mathrm{MH}$. The $\mathrm{MH}$ was shown to be closed at postoperative month 1 and remained closed 3 months after surgery (Fig. 3F). Vision remained stable at 20/100.

\section{ACKNOWLEDGEMENTS}

Funding. No funding or sponsorship was received for this study or the publication of this article.

Authorship. All named authors meet the International Committee of Medical Journal Editors (ICMJE) criteria for authorship for this article, take responsibility for the integrity of the work as a whole, and have given their approval for this version to be published.

Authorship Contributions. Concept and design - Jessica L Cao, Peter K Kaiser. Drafting manuscript - Jessica L Cao. Critical revision of manuscript - Jessica L Cao, Peter K Kaiser. All authors read and approved the final manuscript.

Compliance with Ethics Guidelines. This article is based on previously conducted studies and does not contain any new studies with human participants or animals performed by any of the authors.

Disclosures. Peter K. Kaiser is a consultant for Carl Zeiss Meditec. Jessica L. Cao has nothing to disclose. 
Data Availability. Data sharing is not applicable to this article as no datasets were generated or analyzed during the current study.

Open Access. This article is licensed under a Creative Commons Attribution-NonCommercial 4.0 International License, which permits any non-commercial use, sharing, adaptation, distribution and reproduction in any medium or format, as long as you give appropriate credit to the original author(s) and the source, provide a link to the Creative Commons licence, and indicate if changes were made. The images or other third party material in this article are included in the article's Creative Commons licence, unless indicated otherwise in a credit line to the material. If material is not included in the article's Creative Commons licence and your intended use is not permitted by statutory regulation or exceeds the permitted use, you will need to obtain permission directly from the copyright holder. To view a copy of this licence, visit http://creativecommons.org/licenses/bync/4.0/.

\section{REFERENCES}

1. McCannel CA, Ensminger JL, Diehl NN, Hodge DN. Population-based incidence of macular holes. Ophthalmology. 2009;116(7):1366-9. https://doi. org/10.1016/j.ophtha.2009.01.052.

2. Darian-Smith E, Howie AR, Allen PL, Vote BJ. Tasmanian macular hole study: whole populationbased incidence of full thickness macular hole. Clin Exp Ophthalmol. 2016;44(9):812-6. https://doi. org/10.1111/ceo.12801.

3. Meuer SM, Myers CE, Klein BEK, et al. The epidemiology of vitreoretinal interface abnormalities as detected by spectral-domain optical coherence tomography: the beaver dam eye study. Ophthalmology. 2015;122(4):787-95. https://doi.org/10. 1016/j.ophtha.2014.10.014.

4. Rahmani B, Tielsch JM, Katz J, et al. The causespecific prevalence of visual impairment in an urban population. Baltim Eye Survey Ophthalmol. 1996;103(11):1721-6. https://doi.org/10.1016/ s0161-6420(96)30435-1.

5. Mitchell P, Smith W, Chey T, Wang JJ, Chang A. Prevalence and associations of epiretinal membranes. The Blue Mountains Eye Study, Australia. Ophthalmology. 1997;104(6):1033-40. https://doi.org/10.1016/s0161-6420(97)30190-0.

6. la Cour M, Friis J. Macular holes: classification, epidemiology, natural history and treatment. Acta Ophthalmol Scand. 2002;80(6):579-87. https://doi. org/10.1034/j.1600-0420.2002.800605.x.

7. Sen P, Bhargava A, Vijaya L, George R. Prevalence of idiopathic macular hole in adult rural and urban south Indian population. Clin Exp Ophthalmol. 2008;36(3):257-60. https://doi.org/10.1111/j.14429071.2008.01715.x.

8. The Eye Disease Case-Control Study Group. Risk factors for idiopathic macular holes. Am J Ophthalmol. 1994;118(6):754-61.

9. Evans JR, Schwartz SD, McHugh JD, et al. Systemic risk factors for idiopathic macular holes: a casecontrol study. Eye Lond Engl. 1998;12(Pt 2):256-9. https://doi.org/10.1038/eye.1998.60.

10. Ali FS, Stein JD, Blachley TS, Ackley S, Stewart JM. Incidence of and risk factors for developing idiopathic macular hole among a diverse group of patients throughout the United States. JAMA Ophthalmol. 2017;135(4):299-305. https://doi.org/10. 1001/jamaophthalmol.2016.5870.

11. Cho SC, Park SJ, Byun SJ, Woo SJ, Park KH. Five-year nationwide incidence of macular hole requiring surgery in Korea. Br J Ophthalmol. 2019;103(11): 1619-23. https://doi.org/10.1136/bjophthalmol2018-313237.

12. Bae K, Kang SW, Kim JH, Kim SJ, Kim JM, Yoon JM. Extent of internal limiting membrane peeling and its impact on macular hole surgery outcomes: a randomized trial. Am J Ophthalmol. 2016;169: 179-88. https://doi.org/10.1016/j.ajo.2016.06.041.

13. Sheidow TG, Blinder KJ, Holekamp N, et al. Outcome results in macular hole surgery: an evaluation of internal limiting membrane peeling with and without indocyanine green. Ophthalmology. 2003;110(9):1697-701. https://doi.org/10.1016/ S0161-6420(03)00562-1.

14. Kumagai K, Furukawa M, Ogino N, Uemura A, Demizu S, Larson E. Vitreous surgery with and without internal limiting membrane peeling for macular hole repair. Retina Phila PA. 2004;24(5): 721-7. https://doi.org/10.1097/00006982200410000-00006.

15. Eckardt C, Eckardt U, Groos S, Luciano L, Reale E. Removal of the internal limiting membrane in macular holes. Clinical and morphological findings. Ophthalmol Z Dtsch Ophthalmol Ges. 
1997;94(8):545-51. s003470050156.

https://doi.org/10.1007/

16. Tognetto D, Grandin R, Sanguinetti G, et al. Internal limiting membrane removal during macular hole surgery: results of a multicenter retrospective study. Ophthalmology. 2006;113(8):1401-10. https://doi.org/10.1016/j.ophtha.2006.02.061.

17. Haritoglou C, Reiniger IW, Schaumberger M, Gass CA, Priglinger SG, Kampik A. Five-year follow-up of macular hole surgery with peeling of the internal limiting membrane: update of a prospective study. Retina Phila PA. 2006;26(6):618-22. https://doi.org/ 10.1097/01.iae.0000236474.63819.3a.

18. Smiddy WE, Feuer W, Cordahi G. Internal limiting membrane peeling in macular hole surgery. Ophthalmology. 2001;108(8):1471-6. https://doi.org/ 10.1016/s0161-6420(00)00645-X (discussion 1477-1478).

19. Vaziri K, Schwartz SG, Kishor KS, et al. Rates of reoperation and retinal detachment after macular hole surgery. Ophthalmology. 2016;123(1):26-31. https://doi.org/10.1016/j.ophtha.2015.09.015.

20. Valldeperas X, Wong D. Is it worth reoperating on macular holes? Ophthalmology. 2008;115(1): 158-63. https://doi.org/10.1016/j.ophtha.2007.01. 039.

21. Abbey AM, Van Laere L, Shah AR, Hassan TS. Recurrent macular holes in the era of small-gauge vitrectomy: a review of incidence, risk factors, and outcomes. Retina. 2017;37(5):921-4. https://doi. org/10.1097/IAE.0000000000001252.

22. Paques M, Massin P, Blain P, Duquesnoy AS, Gaudric A. Long-term incidence of reopening of macular holes. Ophthalmology. 2000;107(4):760-5. https://doi.org/10.1016/s0161-6420(99)00182-7 (discussion 766).

23. Duker JS, Wendel R, Patel AC, Puliafito CA. Late reopening of macular holes after initially successful treatment with vitreous surgery. Ophthalmology. 1994;101(8):1373-8. s0161-6420(13)31174-9.

24. Christmas NJ, Smiddy WE, Flynn HW. Reopening of macular holes after initially successful repair. Ophthalmology. 1998;105(10):1835-8. https://doi. org/10.1016/S0161-6420(98)91025-9.

25. Kokame GT. Recurrence of macular holes. Ophthalmology. 1995;102(2):172-3. https://doi.org/10. 1016/s0161-6420(95)31042-1.

26. Yek JTO, Hunyor AP, Campbell WG, McAllister IL, Essex RW, Australian and New Zealand Society of Retinal Specialists Macular Hole Study Group.
Outcomes of eyes with failed primary surgery for idiopathic macular hole. Ophthalmol Retin. 2018;2(8):757-64. https://doi.org/10.1016/j.oret. 2017.10.012.

27. Ip MS, Baker BJ, Duker JS, et al. Anatomical outcomes of surgery for idiopathic macular hole as determined by optical coherence tomography. Arch Ophthalmol Chic Ill. 2002;120(1):29-35. https:// doi.org/10.1001/archopht.120.1.29.

28. Ryan EH, Gilbert HD. Results of surgical treatment of recent-onset full-thickness idiopathic macular holes. Arch Ophthalmol Chic Ill. 1994;112(12): 1545-53. https://doi.org/10.1001/archopht.1994. 01090240051025.

29. Ye T, Yu J-G, Liao L, Liu L, Xia T, Yang L-L. Macular hole surgery recovery with and without face-down posturing: a meta-analysis of randomized controlled trials. BMC Ophthalmol. 2019;19(1):265 . https://doi.org/10.1186/s12886-019-1272-1.

30. Alberti M, la Cour M. Nonsupine positioning in macular hole surgery: a noninferiority randomized clinical trial. Retina Phila PA. 2016;36(11):2072-9. https://doi.org/10.1097/IAE.0000000000001041.

31. Patel SC, Loo RH, Thompson JT, Sjaarda RN. Macular hole surgery in high myopia. Ophthalmology. 2001;108(2):377-80. https://doi.org/10.1016/ s0161-6420(00)00532-7.

32. Steel DH, Donachie PHJ, Aylward GW, et al. Factors affecting anatomical and visual outcome after macular hole surgery: findings from a large prospective UK cohort. Eye Lond Engl. 2021;35(1): 316-25. https://doi.org/10.1038/s41433-020-0844$\mathrm{x}$.

33. Xia S, Zhao X-Y, Wang E-Q, Chen Y-X. Comparison of face-down posturing with nonsupine posturing after macular hole surgery: a meta-analysis. BMC Ophthalmol. 2019;19(1):34. https://doi.org/10. 1186/s12886-019-1047-8.

34. Duker JS, Kaiser PK, Binder S, et al. The international vitreomacular traction study group classification of vitreomacular adhesion, traction, and macular hole. Ophthalmology. 2013;120(12): 2611-9. https://doi.org/10.1016/j.ophtha.2013.07. 042.

35. Ullrich S, Haritoglou C, Gass C, Schaumberger M, Ulbig MW, Kampik A. Macular hole size as a prognostic factor in macular hole surgery. Br J Ophthalmol. 2002;86(4):390-3. https://doi.org/10. 1136/bjo.86.4.390.

36. Kelly NE, Wendel RT. Vitreous surgery for idiopathic macular holes Results of a pilot study. Arch 
Ophthalmol Chic Ill. 1991;109(5):654-9. https:// doi.org/10.1001/archopht.1991.01080050068031.

37. Park DW, Sipperley JO, Sneed SR, Dugel PU, Jacobsen J. Macular hole surgery with internal-limiting membrane peeling and intravitreous air. Ophthalmology. 1999;106(7):1392-7. https://doi.org/10. 1016/S0161-6420(99)00730-7 (discussion 1397-1398).

38. Brooks HL. Macular hole surgery with and without internal limiting membrane peeling. Ophthalmology. 2000;107(10):1939-48. https://doi.org/10. 1016/s0161-6420(00)00331-6 (discussion 1948-1949).

39. Gass JD. Idiopathic senile macular hole. Its early stages and pathogenesis. Arch Ophthalmol Chic Ill. 1988;106(5):629-39. https://doi.org/10.1001/ archopht.1988.01060130683026.

40. Lois N, Burr J, Norrie J, et al. Internal limiting membrane peeling versus no peeling for idiopathic full-thickness macular hole: a pragmatic randomized controlled trial. Invest Ophthalmol Vis Sci. 2011;52(3):1586-92. https://doi.org/10.1167/iovs. $10-6287$.

41. Da Mata AP, Burk SE, Riemann CD, et al. Indocyanine green-assisted peeling of the retinal internal limiting membrane during vitrectomy surgery for macular hole repair. Ophthalmology. 2001;108(7): 1187-92. 6420(01)00593-0.

42. Lochhead J, Jones E, Chui D, et al. Outcome of ICGassisted ILM peel in macular hole surgery. Eye Lond Engl. 2004;18(8):804-8. https://doi.org/10.1038/sj. eye.6701328.

43. Hagiwara A, Baba T, Tatsumi T, Sato E, Oshitari T, Yamamoto S. Functional and morphologic outcomes after reoperation for persistent idiopathic macular hole. Eur J Ophthalmol. 2017;27(2):231-4. https://doi.org/10.5301/ejo.5000857.

44. D'Souza MJJ, Chaudhary V, Devenyi R, Kertes PJ, Lam W-C. Re-operation of idiopathic full-thickness macular holes after initial surgery with internal limiting membrane peel. $\mathrm{Br} \mathrm{J}$ Ophthalmol. 2011;95(11):1564-7. https://doi.org/10.1136/bjo. 2010.195826 .

45. Moisseiev E, Fabian ID, Moisseiev J, Barak A. Outcomes of repeated pars plana vitrectomy for persistent macular holes. Retina Phila PA. 2013;33(6): 1137-43. 0b013e31828076c5.

46. Che X, He F, Lu L, et al. Evaluation of secondary surgery to enlarge the peeling of the internal limiting membrane following the failed surgery of idiopathic macular holes. Exp Ther Med. 2014;7(3): 742-6. https://doi.org/10.3892/etm.2014.1477.

47. Michalewska Z, Michalewski J, Adelman RA, Nawrocki J. Inverted internal limiting membrane flap technique for large macular holes. Ophthalmology. 2010;117(10):2018-25. https://doi.org/10. 1016/j.ophtha.2010.02.011.

48. Rizzo S, Tartaro R, Barca F, Caporossi T, Bacherini D, Giansanti F. Internal limiting membrane peeling versus inverted flap technique for treatment of fullthickness macular holes: a comparative study in a large series of patients. Retina Phila PA. 2018;38(Suppl 1):S73-8. https://doi.org/10.1097/ IAE.0000000000001985.

49. Kuriyama S, Hayashi H, Jingami Y, Kuramoto N, Akita J, Matsumoto M. Efficacy of inverted internal limiting membrane flap technique for the treatment of macular hole in high myopia. Am J Ophthalmol. 2013;156(1):125-131.e1. https://doi.org/ 10.1016/j.ajo.2013.02.014.

50. Michalewska Z, Michalewski J, DulczewskaCichecka K, Nawrocki J. Inverted internal limiting membrane flap technique for surgical repair of myopic macular holes. Retina Phila PA. 2014;34(4): 664-9. 0000000000000042 .

51. Manasa S, Kakkar P, Kumar A, Chandra P, Kumar V, Ravani R. Comparative evaluation of standard ILM peel with inverted ILM flap technique in large macular holes: a prospective, randomized study. Ophthalmic Surg Lasers Imaging Retin. 2018;49(4): 236-40. https://doi.org/10.3928/2325816020180329-04.

52. Kannan NB, Kohli P, Parida H, Adenuga OO, Ramasamy K. Comparative study of inverted internal limiting membrane (ILM) flap and ILM peeling technique in large macular holes: a randomizedcontrol trial. BMC Ophthalmol. 2018;18(1):177. https://doi.org/10.1186/s12886-018-0826-y.

53. Narayanan R, Singh SR, Taylor S, et al. Surgical outcomes after inverted internal limiting membrane flap versus conventional peeling for very large macular holes. Retina Phila PA. 2019;39(8): 1465-9. https://doi.org/10.1097/IAE. 0000000000002186.

54. Michalewska Z, Michalewski J, DulczewskaCichecka K, Adelman RA, Nawrocki J. Temporal inverted internal limiting membrane flap technique versus classic inverted internal limiting membrane flap technique: a comparative study. Retina Phila PA. 2015;35(9):1844-50. https://doi. org/10.1097/IAE.0000000000000555. 
55. Ghassemi F, Khojasteh $\mathrm{H}$, Khodabande A, et al. Comparison of three different techniques of inverted internal limiting membrane flap in treatment of large idiopathic full-thickness macular hole. Clin Ophthalmol Auckl NZ. 2019;13:2599-606. https:// doi.org/10.2147/OPTH.S236169.

56. Major JC, Lampen SIR, Wykoff CC, et al. The Texas taco technique for internal limiting membrane flap in large full-thickness macular holes: a short-term pilot study. Retina Phila PA. 2020;40(3):552-6. https://doi.org/10.1097/IAE.0000000000002431.

57. Morizane Y, Shiraga F, Kimura S, et al. Autologous transplantation of the internal limiting membrane for refractory macular holes. Am J Ophthalmol. 2014;157(4):861-869.e1. https://doi.org/10.1016/j. ajo.2013.12.028.

58. Pires J, Nadal J, Gomes NL. Internal limiting membrane translocation for refractory macular holes. Br J Ophthalmol. 2017;101(3):377-82. https://doi.org/10.1136/bjophthalmol-2015308299.

59. De Novelli FJ, Preti RC, Ribeiro Monteiro ML, Pelayes DE, Junqueira Nóbrega M, Takahashi WY. Autologous internal limiting membrane fragment transplantation for large, chronic, and refractory macular holes. Ophthalmic Res. 2015;55(1):45-52. https://doi.org/10.1159/000440767.

60. Dai Y, Dong F, Zhang X, Yang Z. Internal limiting membrane transplantation for unclosed and large macular holes. Graefes Arch Clin Exp Ophthalmol. 2016;254(11):2095-9. https://doi.org/10.1007/ s00417-016-3461-4.

61. Shin MK, Park KH, Park SW, Byon IS, Lee JE. Perfluoro-n-octane-assisted single-layered inverted internal limiting membrane flap technique for macular hole surgery. Retina Phila PA. 2014;34(9): 1905-10. 0000000000000339.

62. Lai C-C, Wu A-L, Chou H-D, et al. Sub-perfluoro-noctane injection of ocular viscoelastic device assisted inverted internal limiting membrane flap for macular hole retinal detachment surgery: a novel technique. BMC Ophthalmol. 2020;20(1):116. https://doi.org/10.1186/s12886-020-01393-1.

63. Cisiecki S, Bonińska K, Bednarski M. Autologous lens capsule flap transplantation for persistent macular holes. J Ophthalmol. 2021;2021:8148792. https://doi.org/10.1155/2021/8148792.

64. Chen S-N, Yang C-M. Lens capsular flap transplantation in the management of refractory macular hole from multiple etiologies. Retina Phila PA. 2016;36(1):163-70. https://doi.org/10.1097/IAE. 0000000000000674 .
65. Peng J, Chen C, Zhang H, et al. Long-term surgical outcomes of lens capsular flap transplantation in the management of refractory macular hole. Retina Phila PA. 2021;41(4):726-34. https://doi.org/10. 1097/IAE.0000000000002922.

66. Grewal DS, Mahmoud TH. Autologous neurosensory retinal free flap for closure of refractory myopic macular holes. JAMA Ophthalmol. 2016;134(2): 229-30. https://doi.org/10.1001/jamaophthalmol. 2015.5237.

67. Grewal DS, Charles S, Parolini B, Kadonosono K, Mahmoud TH. Autologous retinal transplant for refractory macular holes: multicenter international collaborative study group. Ophthalmology. 2019;126(10):1399-408. https://doi.org/10.1016/j. ophtha.2019.01.027.

68. Ding C, Li S, Zeng J. Autologous neurosensory retinal transplantation for unclosed and large macular holes. Ophthalmic Res. 2019;61(2):88-93. https://doi.org/10.1159/000487952.

69. Chang Y-C, Liu P-K, Kao T-E, et al. Management of refractory large macular hole with autologous neurosensory retinal free flap transplantation. Retina Phila PA. 2020;40(11):2134-9. https://doi.org/10. 1097/IAE.0000000000002734.

70. Tanaka S, Inoue M, Inoue T, et al. Autologous retinal transplantation as a primary treatment for large chronic macular holes. Retina Phila PA. 2020;40(10):1938-45. https://doi.org/10.1097/IAE. 0000000000002693 .

71. Rojas-Juárez S, Cisneros-Cortés J, Ramirez-Estudillo A, Velez-Montoya R. Autologous full-thickness retinal transplant for refractory large macular holes. Int J Retina Vitr. 2020;6(1):60. https://doi.org/10. 1186/s40942-020-00266-5.

72. Rizzo S, Caporossi T, Tartaro R, et al. A human amniotic membrane plug to promote retinal breaks repair and recurrent macular hole closure. Retina Phila PA. 2019;39(Suppl 1):S95-103. https://doi. org/10.1097/IAE.0000000000002320.

73. Caporossi T, Tartaro R, Finocchio L, et al. Human amniotic membrane to treat macular holes that failed to close, sulfur hexafluoride endotamponade versus air endotamponade: a prospective comparative study. Retina Phila PA. 2021;41(4):735-43. https://doi.org/10.1097/IAE.0000000000002913.

74. Caporossi T, Pacini B, Bacherini D, Barca F, Faraldi F, Rizzo S. Human amniotic membrane plug to promote failed macular hole closure. Sci Rep. 2020;10(1):18264. https://doi.org/10.1038/s41598020-75292-2. 
75. Ferreira MA, Maia A, Machado AJ, et al. Human amniotic membrane for the treatment of large and refractory macular holes: a retrospective, multicentric, interventional study. Int J Retina Vitr. 2021;7(1):38. https://doi.org/10.1186/s40942-02100308-6.

76. Yadav NK, Venkatesh R, Thomas S, Pereira A, Shetty KB. Novel method of plugging the hole: anatomical and functional outcomes of human amniotic membrane-assisted macular hole surgery. J Curr Ophthalmol. 2020;32(4):361-7. https://doi.org/10. 4103/JOCO.JOCO_189_20.

77. Ksander GA, Sawamura SJ, Ogawa Y, Sundsmo J, McPherson JM. The effect of platelet releasate on wound healing in animal models. J Am Acad Dermatol. 1990;22(5 Pt 1):781-91. https://doi.org/10. 1016/0190-9622(90)70109-u.

78. Gaudric A, Massin P, Paques M, et al. Autologous platelet concentrate for the treatment of fullthickness macular holes. Graefes Arch Clin Exp Ophthalmol. 1995;233(9):549-54. https://doi.org/ 10.1007/BF00404704.

79. Paques M, Chastang C, Mathis A, et al. Effect of autologous platelet concentrate in surgery for idiopathic macular hole: results of a multicenter, double-masked, randomized trial. Platelets in Macular Hole Surgery Group. Ophthalmology. 1999;106(5):932-8. https://doi.org/10.1016/s01616420(99)00512-6.

80. Vote BJ, Membrey WL, Casswell AG. Autologous platelets for macular hole surgery: the Sussex Eye Hospital experience. Clin Exp Ophthalmol. 2004;32(5):472-7. https://doi.org/10.1111/j.14429071.2004.00866.x.

81. Cheung CMG, Munshi V, Mughal S, Mann J, Hero $\mathrm{M}$. Anatomical success rate of macular hole surgery with autologous platelet without internal-limiting membrane peeling. Eye Lond Engl. 2005;19(11): 1191-3. https://doi.org/10.1038/sj.eye.6701733.

82. Shpak AA, Shkvorchenko DO, Krupina EA. Surgical treatment of macular holes with and without the use of autologous platelet-rich plasma. Int
Ophthalmol. 2021;41(3):1043-52. https://doi.org/ 10.1007/s10792-020-01662-4.

83. Meyer $\mathrm{CH}$, Borny R, Horchi N. Subretinal fluid application to close a refractory full thickness macular hole. Int J Retina Vitr. 2017;3:44. https:// doi.org/10.1186/s40942-017-0094-7.

84. Oliver A, Wojcik EJ. Macular detachment for treatment of persistent macular hole. Ophthalmic Surg Lasers Imaging. 2011;42(6):516-8. https://doi.org/ 10.3928/15428877-20110825-01.

85. Meyer CH, Szurman P, Haritoglou C, et al. Application of subretinal fluid to close refractory full thickness macular holes: treatment strategies and primary outcome: APOSTEL study. Graefes Arch Clin Exp Ophthalmol. 2020;258(10):2151-61. https://doi.org/10.1007/s00417-020-04735-3.

86. Szigiato A-A, Gilani F, Walsh MK, Mandelcorn ED, Muni RH. Induction of macular detachment for the treatment of persistent or recurrent idiopathic macular holes. Retina Phila PA. 2016;36(9):1694-8. https://doi.org/10.1097/IAE.0000000000000977.

87. Felfeli T, Mandelcorn ED. Macular hole hydrodissection: surgical technique for the treatment of persistent, chronic, and large macular holes. Retina Phila PA. 2019;39(4):743-52. https://doi.org/10. 1097/IAE.0000000000002013.

88. Charles S, Randolph JC, Neekhra A, Salisbury CD, Littlejohn N, Calzada JI. Arcuate retinotomy for the repair of large macular holes. Ophthalmic Surg Lasers Imaging Retina. 2013;44(1):69-72. https:// doi.org/10.3928/23258160-20121221-15.

89. Reis R, Ferreira N, Meireles A. Management of stage IV macular holes: when standard surgery fails. Case Rep Ophthalmol. 2012;3(2):240-50. https://doi. org/10.1159/000342007.

90. Karacorlu M, Sayman Muslubas I, Hocaoglu M, Arf S, Ersoz MG. Double arcuate relaxing retinotomy for a large macular hole. Retin Cases Brief Rep. 2019;13(2):167-70. https://doi.org/10.1097/ICB. 0000000000000551 . 